\title{
A DATA ACQUISITION SYSTEM FOR PROPORTIONAL COUNTERS AT GLIWICE
}

\author{
ADAM MICHCZYŃSKI, TOMASZ GOSLAR, ANNA PAZDUR and MIECZYSEAW F. PAZDUR ${ }^{1}$
}

\author{
Department of Radioisotopes, Silesian Technical University, Bolesława Krzywoustego 2 \\ PL-44-100 Gliwice, Poland
}

\begin{abstract}
We present here the principal ideas of a new, fully computerized data acquisition system with pulıe-rise background reduction, developed in the Gliwice Radiocarbon Laboratory, and our first results. The new system uses a microprocessor-controlled pulse and coincidence analyzer for acquisition of data from 3 of 4 proportional counter sets. The analyzer acquires and stores information on the pulse's amplitudes and rise-times and their coincidence with guard counters and radiofrequency shield. This feature allows us to separate pulses using anticoincidence information and pulse-shape discrimination. The described method of background reduction led to a significant increase in the factor of merit on 2 of 3 counters tested.
\end{abstract}

\section{INTRODUCTION}

After four decades of development in radiocarbon dating using proportional counting techniques, technological improvements can still be made. Many ${ }^{14} \mathrm{C}$ laboratories routinely using gas-proportional counting strive to improve system parameters, primarily through the quality of the counting system - dating range and factor of merit (fM). One of the most promising areas of improvement is background reduction by pulse-shape discrimination. The method is based on a well-known feature, that the pulses generated inside the $\mathrm{CO}_{2}$-filled proportional counter by $\beta$ particles and by cosmic radiation have different shapes. Application of this feature for rejection of pulses generated by cosmic radiation not detected by anticoincidence guard, may result in $>70 \%$ background reduction, causing a $20 \%$ simultaneous reduction of the counting efficiency of ${ }^{14} \mathrm{C} \beta$ particles (Mäntynen et al. 1987; Aikää, Mäntynen and Kankainen 1992). The measurement system, which may acquire data necessary for the pulse-height and rise-time analysis, was developed at the Gliwice Radiocarbon Laboratory.

\section{METHODS}

The Gliwice Radiocarbon Laboratory has four counting systems of proportional counters in passive and active shields (Geiger-Müller counters). The new data acquisition system for single proportional counters consists of four lines: 1) for signals from the counter; 2,3 ) a two-section anticoincidence shield $^{2}$; and 4) radio-frequency shield. Figure 1 shows a schematic diagram of this system. The signals from the proportional counter and anticoincidence Geiger-Müller counters are coupled with low-noise preamplifiers based on the fast operational amplifier LF356. Pulses are amplified and passed through the low-threshold discriminator. The signals from the proportional counter are then analyzed by a microprocessor-controlled pulse and coincidence analyzer, based on a single-chip microcomputer 8051 . Pulses from the proportional counter are digitized by the analog-to-digital converter PNA 7509 ( 7 bits, 128 channels) with a sampling rate of about $10 \mathrm{MHz}$ and temporarily stored to the first part of analyzer RAM. The microprocessor uses the stored digitized pulse for calculation of its pulse-height and rise-time values. With information on the simultaneous detection of anticoincidence shield pulses or radio-frequency noise (RF-shield pulses) these values are stored in the second RAM. Finally, each pulse is stored as 7 bits for pulse height, 8 bits for rise time, 2 bits for signals from two sections of the anticoincidence shield and 1 bit for the RF-shield signal. Pulses

\footnotetext{
${ }^{1}$ Deceased 11 May 1995

${ }^{2}$ The multiwire, tube-shape GM guards of the proportional counters L2 and L3 (horizontal situation) are split into upper and lower sections. The two sections of the guard for L1 (vertical situation) are the set of GMs above and multiwire GM around the main counter. This construction of shields is associated with a method of counting efficiency control.
} 
detected simultaneously at both sections of the anticoincidence shield are also counted in a binary scaler. The information stored in RAM of the analyzer (part 2) and the system binary scalers are sent every $5 \mathrm{~min}$ to the IBM PC computer, which controls the measurements, separates anticoincidence and coincidence pulses, removes pulses detected synchronically with RF noise, performs preliminary statistical analysis of data and calculates the ${ }^{14} \mathrm{C}$ activity of the sample. The software, written in Turbo Pascal ${ }^{\circledR}$, stores all calculated ${ }^{14} \mathrm{C}$-activity data on disk files. This allows connections to another program that calculates radiocarbon ages.

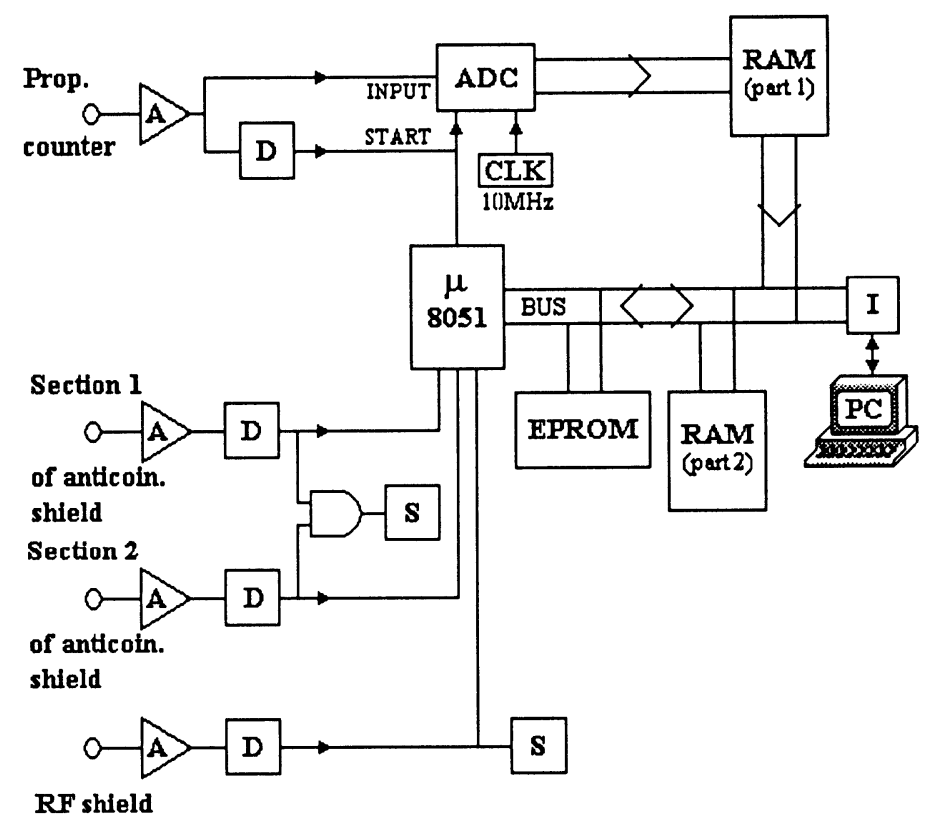

Fig. 1. Schematic diagram of the new data acquisition system for a single counter

\section{RESULTS}

The data acquisition system operates on the well-tested method of counting efficiency and gas purity control, developed in Gliwice in the 1970s (Pazdur, Walanus and Mościcki 1978; Walanus 1986). This method is based on the registration of the number $\mathbf{N}$ of coincident muon counts between the two sections of guard counters in addition to the number $\mathrm{L}$ of coincident counts between the proportional counter and the whole guard. The ratio $\mathrm{C}=\mathrm{L} / \mathrm{N}$ does not depend on muon flux and gives information about counting efficiency. The results obtained are used for the current radiocarbon age calculation. The new system acquires at the same time all data necessary for pulse-shape analysis (pulse-height and rise-time spectra). We use these data for developing and testing our method of pulse-shape discrimination.

The results presented here were obtained for three counting systems-L1, L2 and L3 (Mościcki and Zastawny 1977; Pazdur and Pazdur 1986; Goslar et al. 1990). Table 1 shows basic information about the proportional counters from these counting systems. Figures 2 and 3 show examples of pulse-height and rise-time spectra from the L2 counting system. In Figure 2A, we note differences in rise-time spectra of pulses of the modern biosphere standard obtained in coincidence and anticoincidence with the Geiger-Müller shield. More pulses with short rise times are in the anticoincidence 
than in the coincidence spectrum. Because the proportional counters were filled with the relatively high activity sample (NIST oxalic acid standard SRM 4990C, HOxII), $\beta$ particles originating from the ${ }^{14} \mathrm{C}$ isotope were the main source of pulses in rise-time spectrum of anticoincidence events. On the other hand, the coincidence events are generated by cosmic radiation. The rise-time spectrum for coincidence events of the background (Fig. 2B) is similar to that of the standard. ${ }^{3}$ Unlike the spectrum of anticoincidence events of the standard, the spectrum of anticoincidence events of the background comprises many pulses with long rise times-the same as the spectrum of coincidence events. This group of pulses is caused by cosmic rays that are not fully detected by the anticoincidence guard and radiative contamination in the proportional counter and material shield. Therefore, rejection of these pulses gives the effect of background reduction. The pulse-height spectra presented in Figure 3 show that the anticoincidence pulses of the standard have generally lower amplitudes than those of the background. However, this effect is not large.

TABLE 1. Basic Information for Proportional Counters L1, L2 and L3

\begin{tabular}{llll}
\hline & \multicolumn{3}{c}{ Counter } \\
\cline { 2 - 4 } & L1 & L2 & L3 \\
\hline Volume (dm ${ }^{3}$ ) & 2.9 & 3.8 & 1.5 \\
Diameter (cm) & 9 & 10 & 8 \\
Working voltage (V) & a) $~ 6000$ & $\sim 9000$ & $\sim 6500$ \\
Working pressure (hPa) & b) $~ 9000$ & & \\
& a) 1000 & 2000 & 1000 \\
Direction of axis & b) 2000 & & Horizontal \\
Background (cpm) & Vertical & Horizontal & \\
No pulse-rise discr. & a) 7.27 & 7.70 & 2.85 \\
Optimum pulse-rise discr. & b) 8.22 & & \\
& a) not tested & 2.57 & 1.60 \\
Modern standard (cpm) & b) 3.10 & & \\
No pulse-rise discr. & a) 19.01 & 44.03 & 10.51 \\
Optimum pulse-rise discr. & b) 37.36 & & \\
& a) not tested & 35.53 & 8.49 \\
f) 27.25 & & \\
No pulse-rise discr. & a) 7.05 & 15.87 & 6.21 \\
Optimum pulse-rise discr. & b) 13.03 & & \\
& a) not tested & 22.14 & \\
\hline
\end{tabular}

\footnotetext{
${ }^{3}$ The slight difference in the coincidence spectrum of background and coincidence spectrum of standard is due to different gas purities.
} 


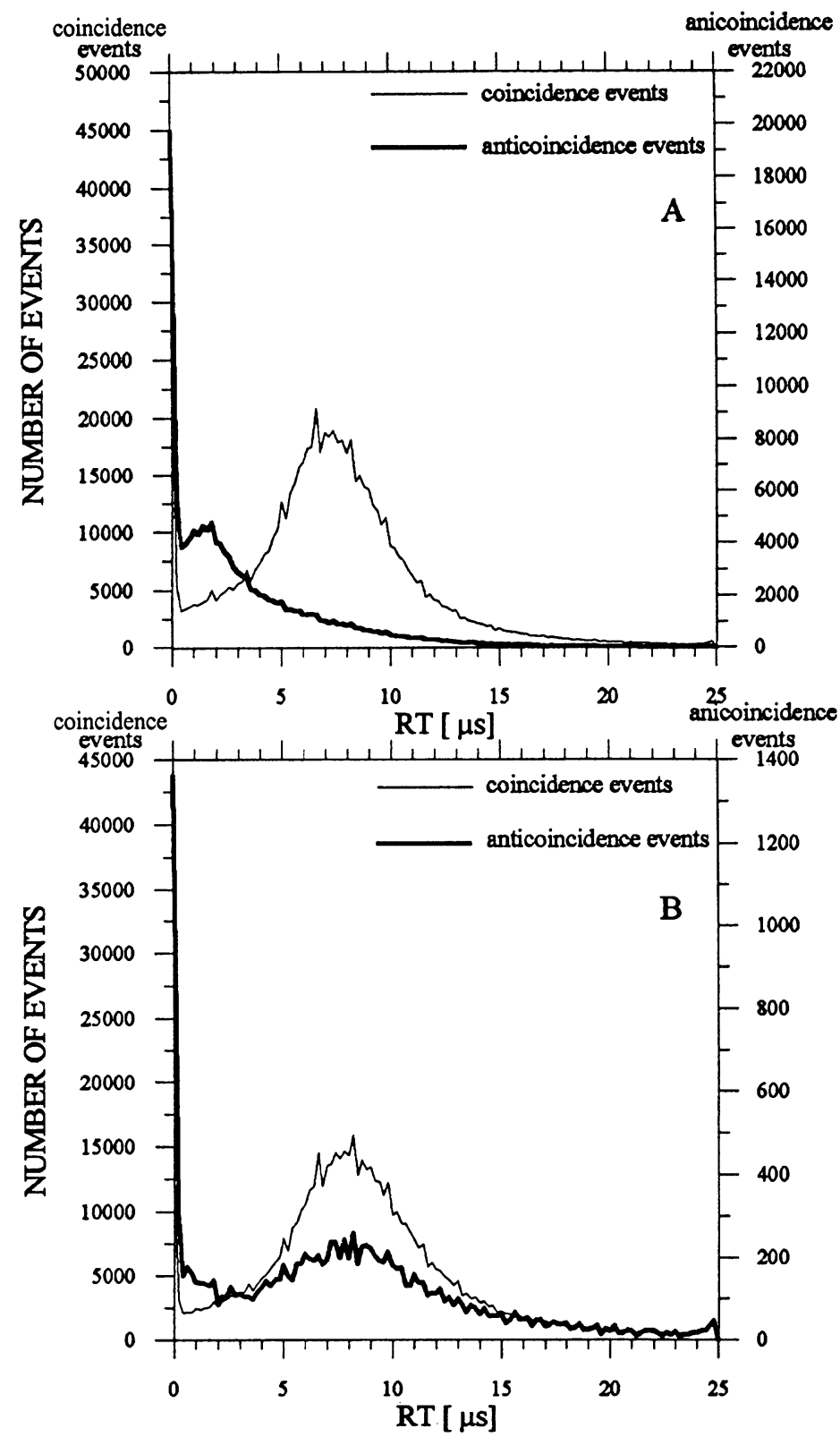

Fig. 2. A. Rise-time spectra of standard SRM 4990C of the modern biosphere from proportional counter L2. B. Rise-time spectra of the background from proportional counter $\mathrm{L} 2$.

Because the differences between pulse-height spectra of anticoincidence events for standard and background do not seem as significant as differences of rise-time spectra, we decided to use only rise-time spectra for background reduction. The diagrams in Figure 4 show the reduction in the counting rate (for background and standard) by the rejection of pulses with rise times greater than 


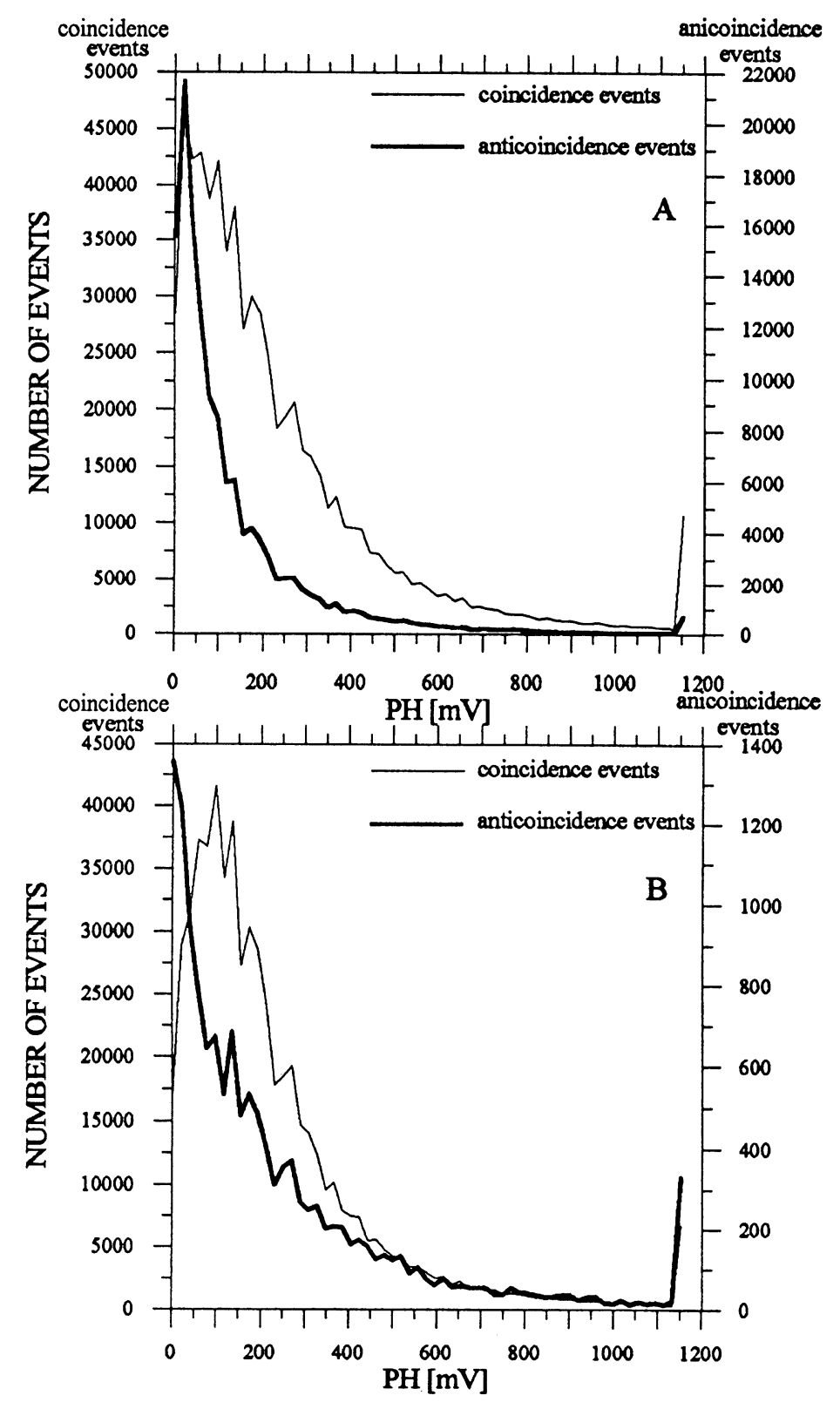

Fig. 3. A. Pulse-height spectra of standard SRM 4990C of the modern biosphere from proportional counter L2. B. Pulse-height spectra of background from proportional counter L2.

the selected value (discrimination level) for counting systems L1, L2 and L3. Table 1 shows the estimated value of counting rates and the $\mathrm{fM}$ after reduction; the significant rise of the $\mathrm{fM}$ after reduction is especially apparent for counter L2. The insignificant change in $\mathrm{fM}$ for counter L3 is probably due to the fact that the working pressure is less than that for counters L1 and L2. 
A - Counter L1

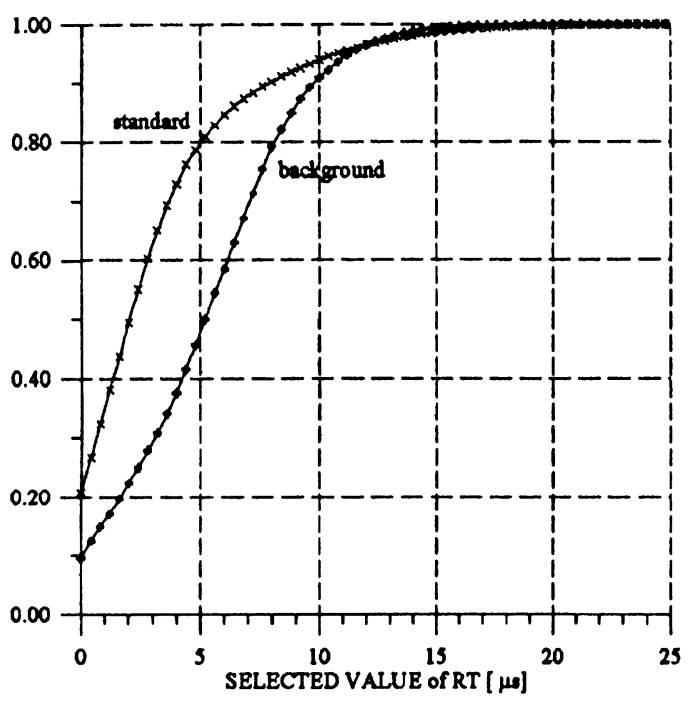

\section{C - Counter L3}

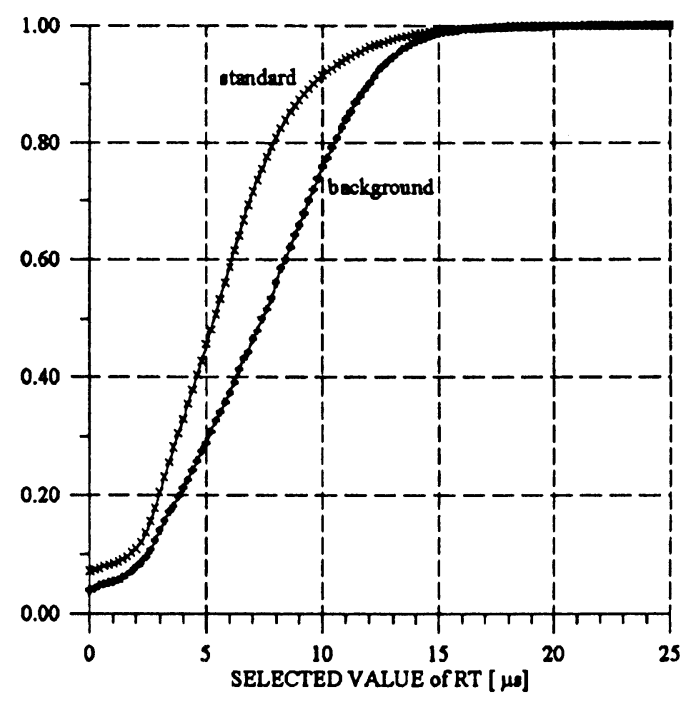

B - Counter L2

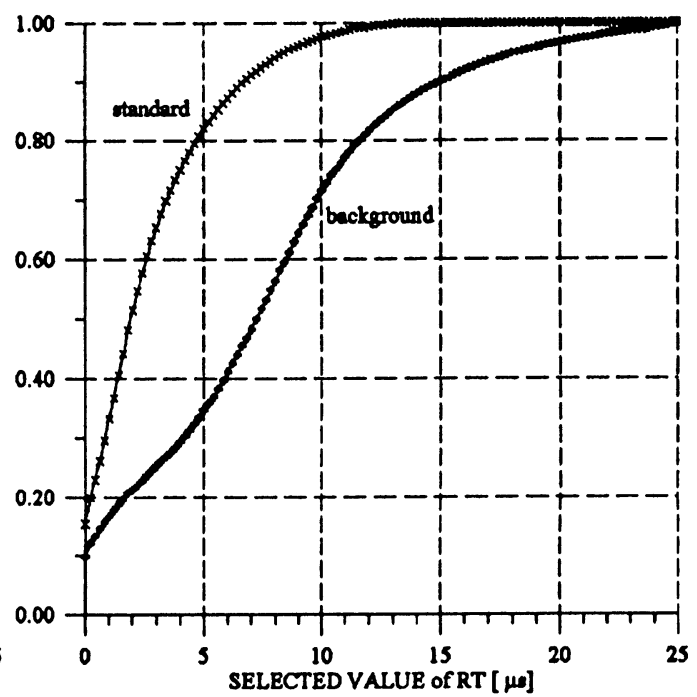

Fig. 4. Residual values of standard and background count rates after rise-time discrimination by eliminating the part of spectrum with rise times greater than the selected value (channel) for A-counter L1, Bcounter $\mathrm{L} 2$ and $\mathrm{C}-$ counter $\mathrm{L} 3$. The results are normalized to a count rate with no rise-time discrimination.

\section{CONCLUSION}

The new data acquisition system employed at the Gliwice Radiocarbon Laboratory includes welltested methods of counting efficiency control and enables background reduction by pulse-shape analysis. The method that we have developed for this reduction leads to a significant rise in $\mathrm{fM}$ for 2 of the 3 counters that were tested. Before we can apply this method to routine ${ }^{14} \mathrm{C}$ dating, however, further tests on long-term stability must be performed. 


\section{REFERENCES}

Aikää, O., Mäntynen, P. and Kankainen, T. 1992 Highperformance ${ }^{14} \mathrm{C}$ gas-proportional counting system applying pulse-shape discrimination. In Long, A. and Kra, R. S., eds., Proceedings of the 14th International ${ }^{14} \mathrm{C}$ Conference. Radiocarbon 34(3): 414-419.

Goslar, T., Pazdur, A., Pazdur, M. F., Walanus, A. and Zastawny, A. 1990 Stanowisko licznika L2 używane w pomiarach ${ }^{14} \mathrm{C}$ o podwyższonej dokładności (Setup of proportional counter $\mathrm{L} 2$ for ${ }^{14} \mathrm{C}$ measurements with improved precision). Zeszyty Naukowe Politechniki Slqskiej, Seria Matematyka-Fizyka, Geochronometria 6: 83-89 (in Polish).

Mäntynen, P., Aikää, O., Kankainen, T. and Kaihola, L. 1987 Application of pulse-shape discrimination to improve the precision of the carbon-14 gas-proportionalcounting method. Applied Radiation Isotopes 38(10): 869-873.

Mościcki, W. and Zastawny, A. 1977 New proportional counter assembly in Gliwice ${ }^{14} \mathrm{C}$ Laboratory. In Po- vinec, P. and Usacev, S., eds., Low-Radioactivity Measurements and Applications. Bratislava, Slovensky Pedagog. Naklad: 91-92.

Pazdur, A. and Pazdur, M. F. 1986 Aparatura pomiarowa Laboratorium ${ }^{14} \mathrm{C}$ w Gliwicach. Doswiadczenia konstrukcyjne i eksploatacyjne (The measuring equipment of the Gliwice Radiocarbon Laboratory. Experience gathered in its construction and exploitation). Zeszyty Naukowe Politechniki Slaskiej, Seria Matematyka-Fizyka, Geochronometria 1: 55-69 (in Polish). Pazdur, M. F., Walanus, A. and Moscicki, W. 1978 A method of continuous examination of counting efficiency during measurements of natural radiocarbon by $\mathrm{CO}_{2}$ filled proportional counter. Nuclear Instruments and Methods in Physics Research 151: 541-547.

Walanus, A. $1986{ }^{14} \mathrm{C}$ electronic measurement system with a microcomputer. In Stuiver, M. and Kra, R., eds., Proceedings of the 12 th International ${ }^{14} \mathrm{C}$ Conference. Radiocarbon 28(2A): 569-570. 